\title{
After us the deluge
}

KADIR VAN LOHUIZEN

AWARD-WINNING DUTCH PHOTOJOURNALIST

Kadir van Lohuizen's recent photo essay 'After Us The Deluge' shows the consequences of rising sea levels for mankind. He travelled to six different regions in the world (Greenland, US, Bangladesh, the Netherlands, UK, and the Pacific) and captured the effects of global warming. The following three photos are selected from this essay and reflect the challenges of water in times of climate change. 


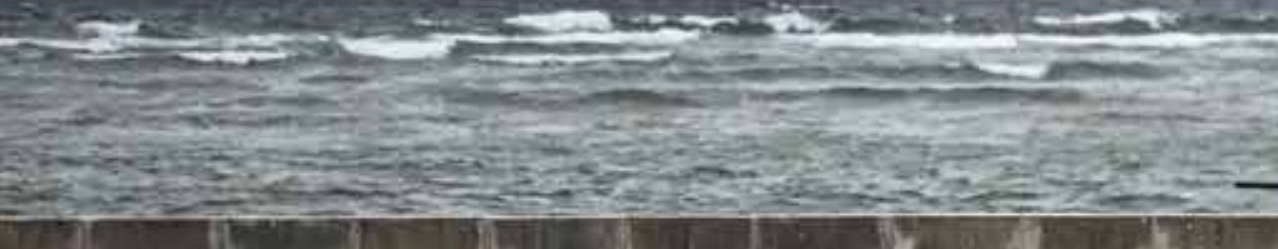

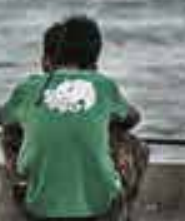

It Thent

Texow $x$

hos
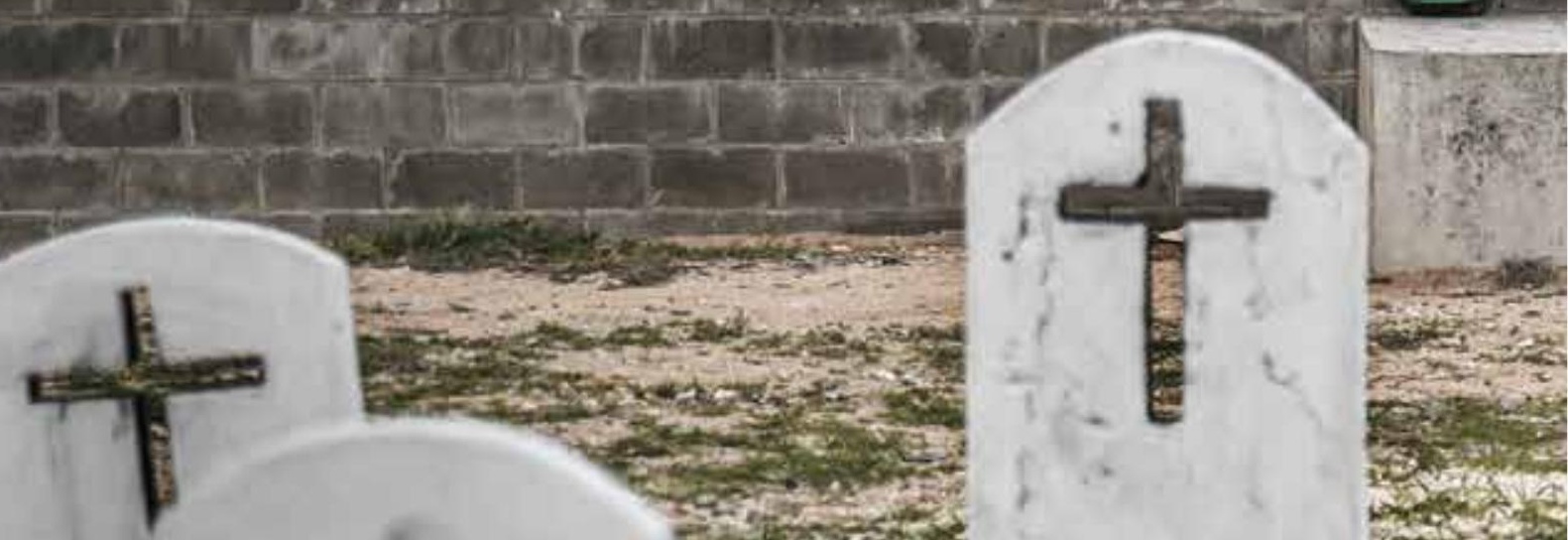

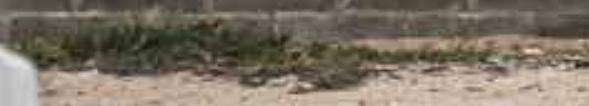

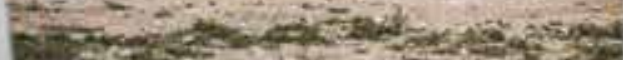
Sor

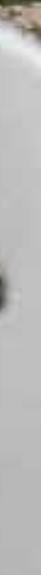

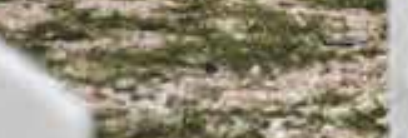

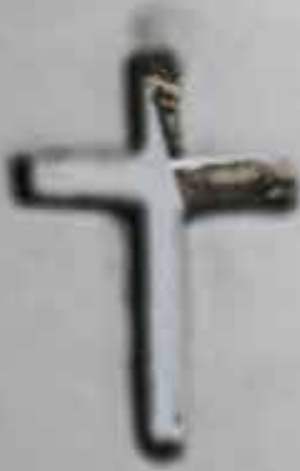

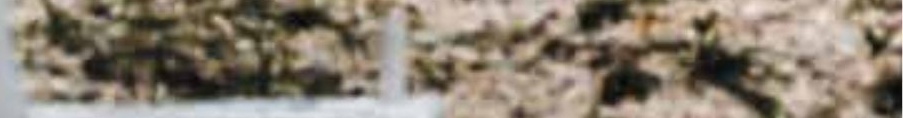

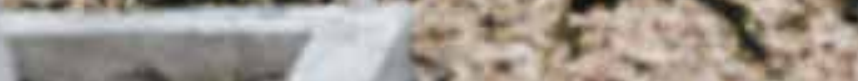




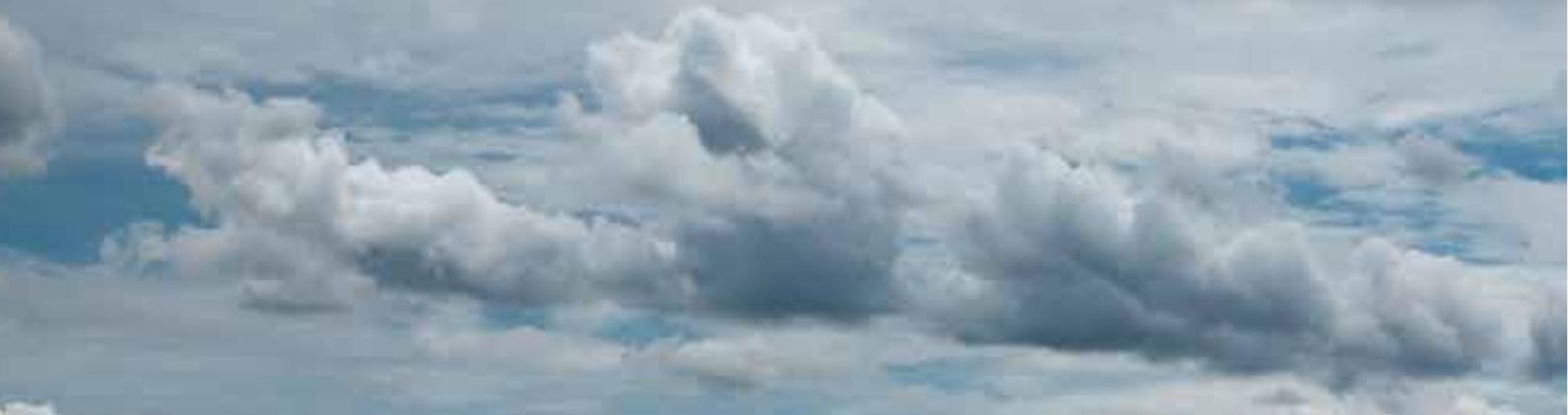

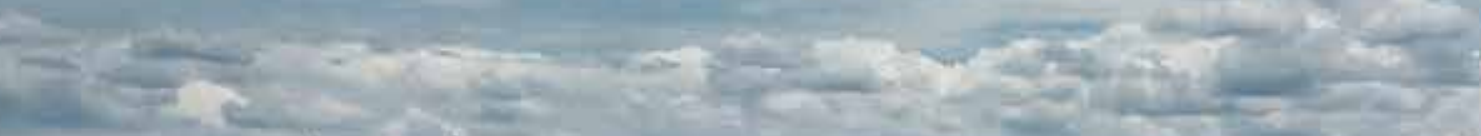

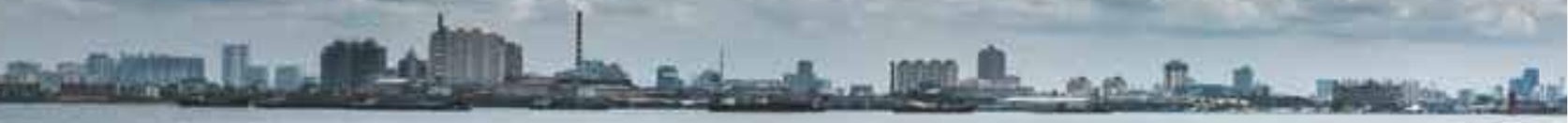

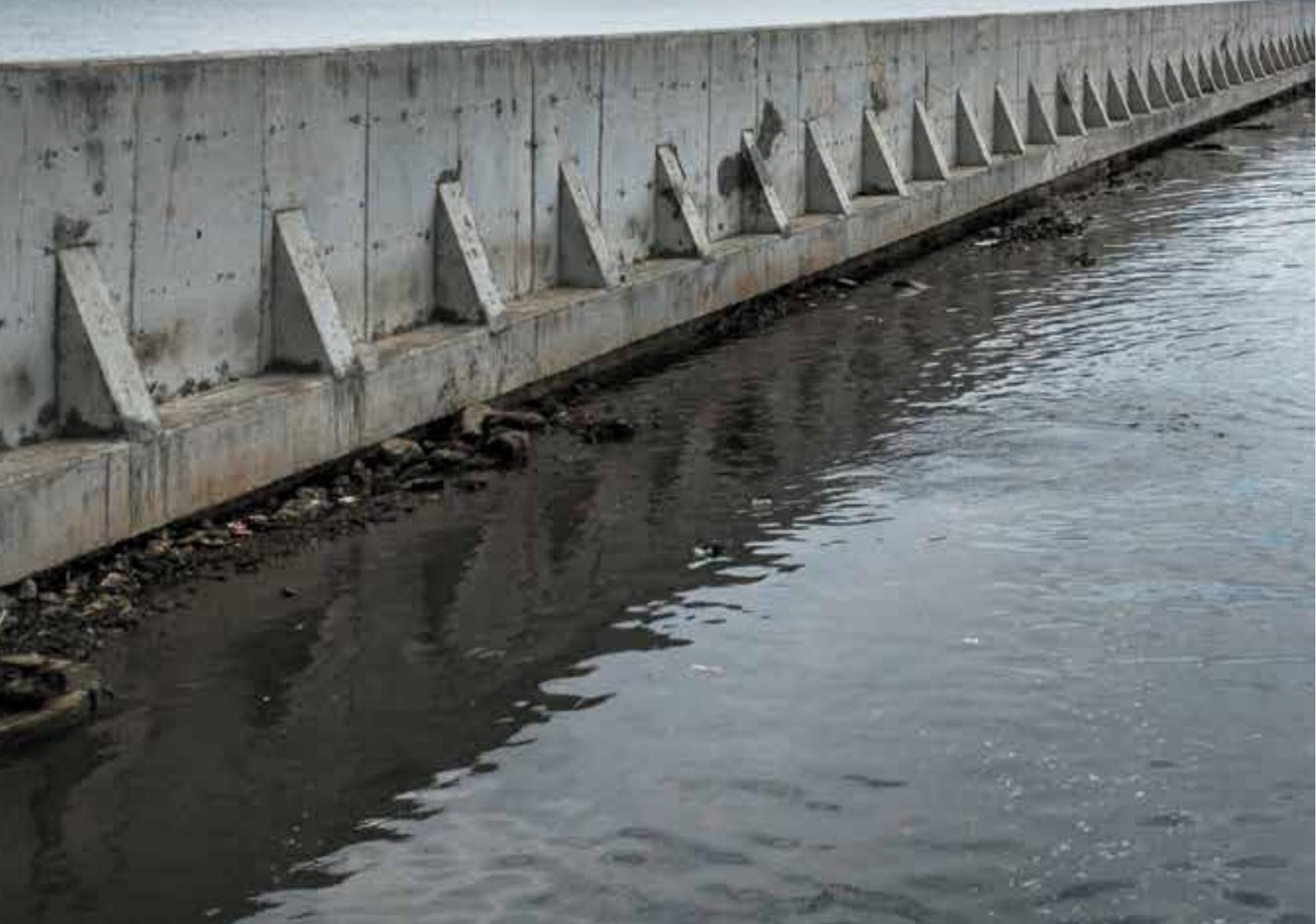



Wuyoyose
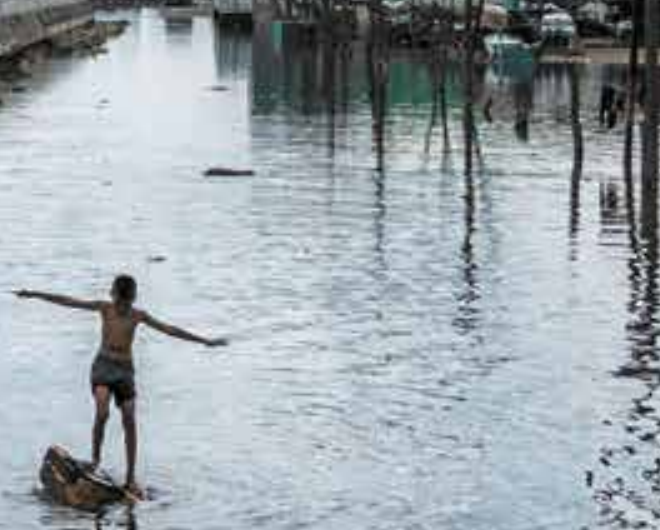

1. $y$ का

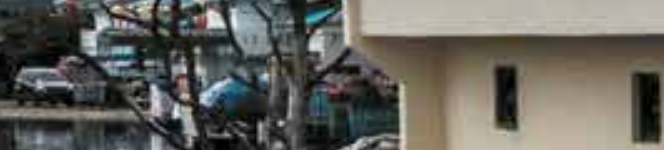

के

a $=120$

1 (3) 2

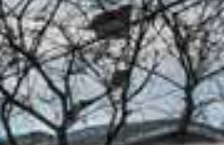




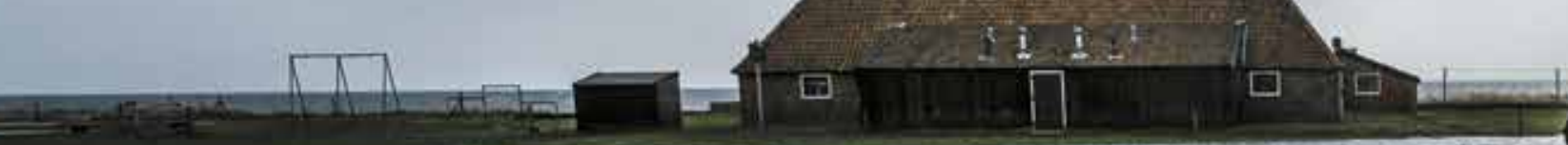

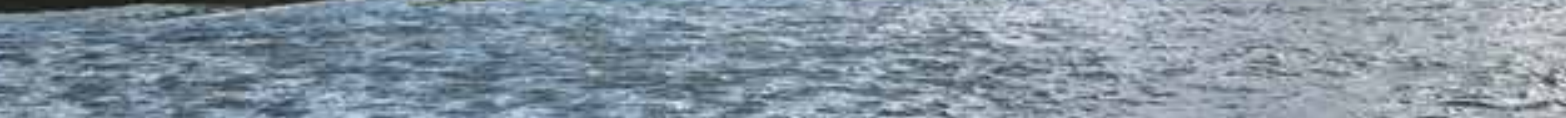

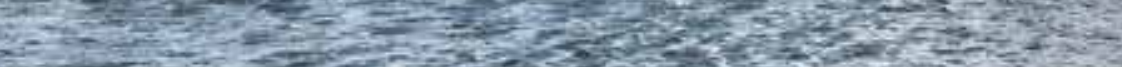

SE-

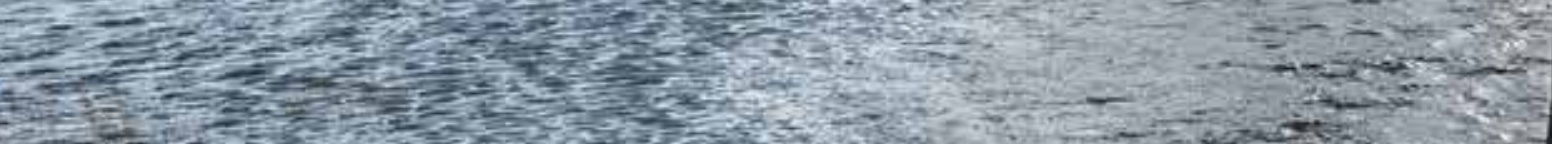

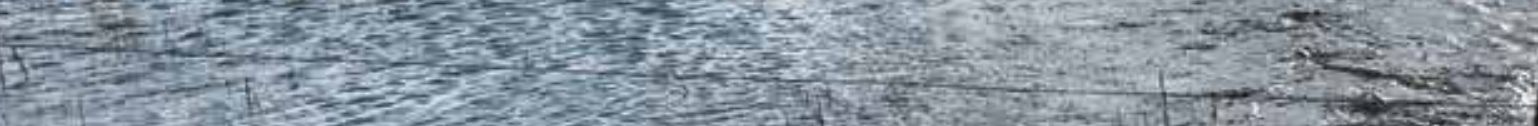

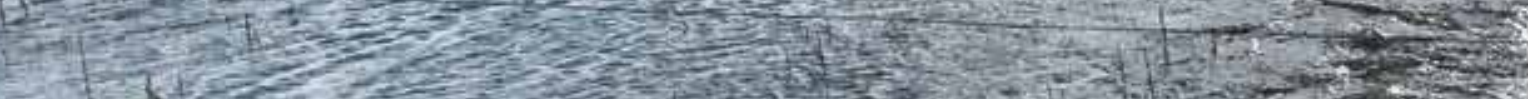

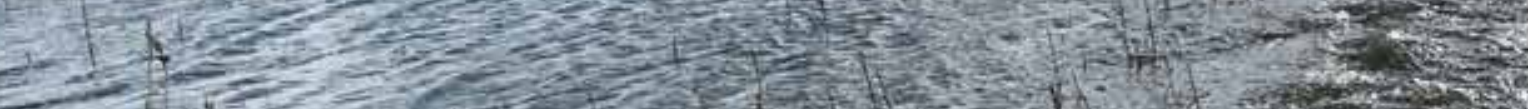

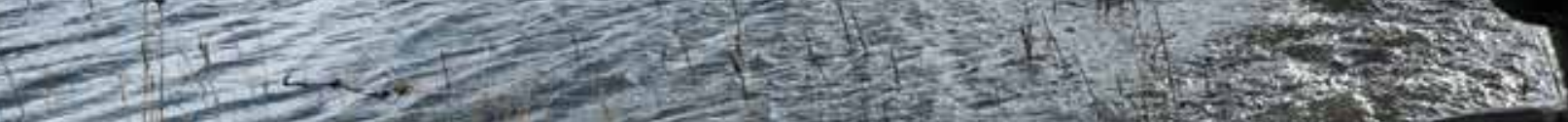

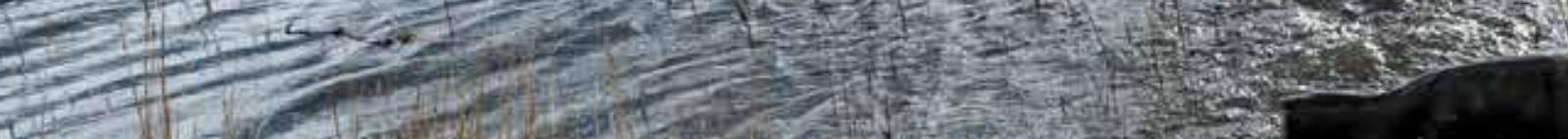

(1) 


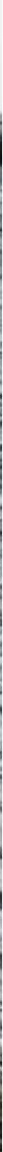

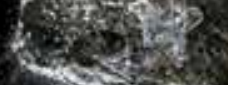

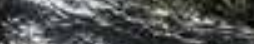

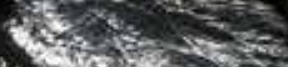

ind

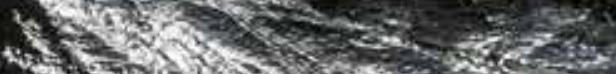

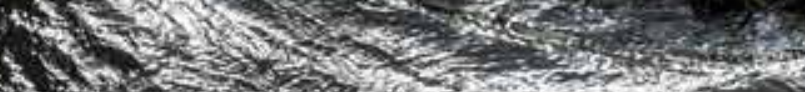

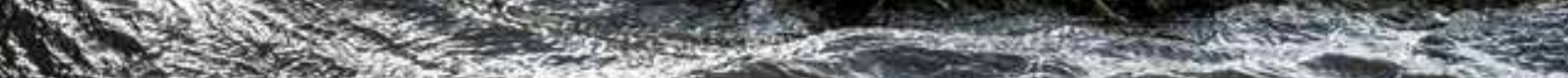

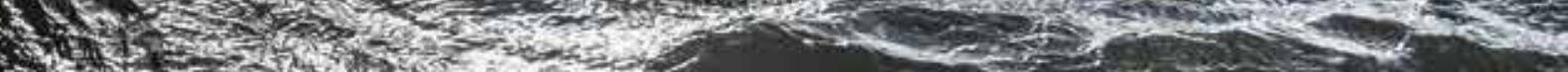

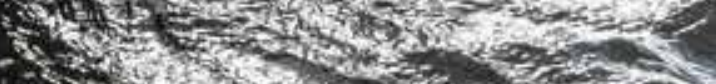

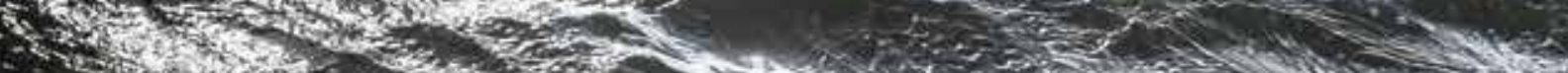

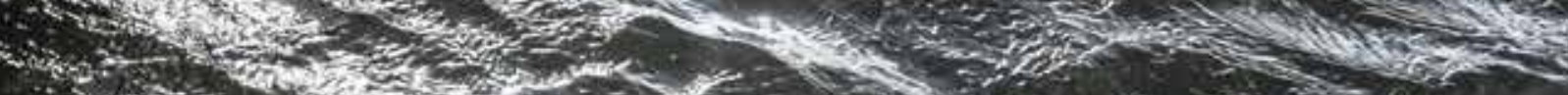

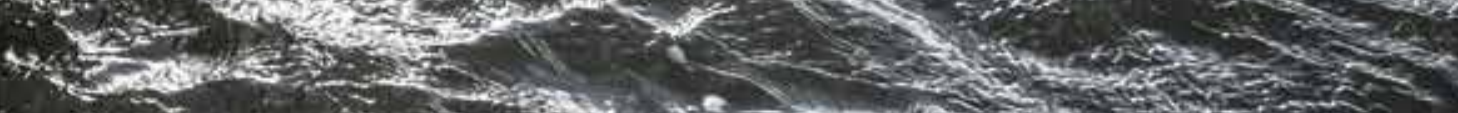

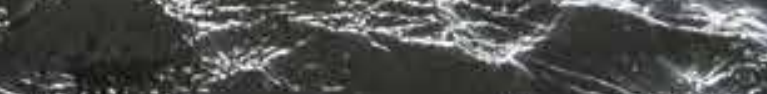

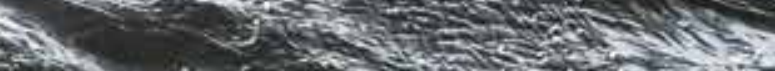

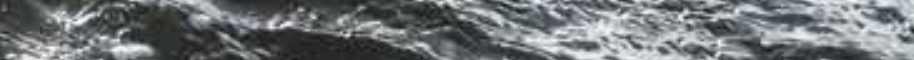

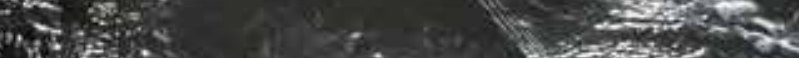


